\title{
PREVALENCE OF HYPOTHYROIDISM IN URBAN POPULATION OF DIBRUGARH TOWN
}

\author{
Pranjal Kumar Dutta1, Anupam Dutta², Himadri Kashyap³, Harry Kaur, Angshuman Boruah ${ }^{5}$, Arushmita Gogoi ${ }^{6}$
}

${ }_{1}^{1}$ Assistant Professor, Department of Medicine, Assam Medical College and Hospital, Dibrugarh, Assam. ${ }^{2}$ Assistant Professor, Department of Medicine, Assam Medical College and Hospital, Dibrugarh, Assam. 3 Senior Research Fellow, Department of Medicine, Assam Medical College and Hospital, Dibrugarh, Assam. 4Junior Research Fellow, Department of Medicine, Assam Medical College and Hospital, Dibrugarh, Assam. ${ }_{5}^{5}$ Statistician, Department of Medicine, Assam Medical College and Hospital, Dibrugarh, Assam. ${ }^{6}$ Medical Social Worker, Department of Medicine, Assam Medical College and Hospital, Dibrugarh, Assam.

\begin{tabular}{l}
\hline ABSTRACT \\
BACKGROUND \\
Prevalence of hypothyroidism in India is higher compared to UK and USA. It is also higher in cities of India located inland in \\
comparison to those located in coastal areas.
\end{tabular}
Aims- We aimed to study the prevalence of hypothyroidism in urban population of Dibrugarh town of Upper Assam.

\section{MATERIALS AND METHODS}

This was a cross-sectional, community-based epidemiological study conducted in four community clinics, in four different wards of Dibrugarh town. All male and female natives of Dibrugarh town, aged $>12$ years of age were asked to volunteer in thyroid camps held on every 2nd and 4th Friday and Saturday of every month from 1st January 2015 to 31st December 2016. Participants were excluded if they were seriously ill, pregnant, had thyroid surgery or on any drugs containing heavy metals (Lithium, Amiodaro ne), steroids (oral or inhaled). TSH, T3 and T4 was done and analysed in all patients.

\section{RESULTS}

A total of 1467 patients were screened, of which 117 patients were excluded due to inadequate data. 1350 patients were included in our study. Their mean age was $42.7(+1.3 \mathrm{SD})$ years. $780(57.78 \%)$ patients had normal thyroid results. $213(15.78 \%)$ patients had overt hypothyroidism and 298 (22.07\%) patients had subclinical hypothyroidism. 41 (3.04\%) had hyperthyroidism and 17 (1.26\%) had subclinical hyperthyroidism.

\section{CONCLUSION}

The urban population of Dibrugarh town shows higher prevalence of clinical as well as subclinical hypothyroidism than Indian average and its results resemble the studies done in hilly areas like Jammu and Kashmir than other inland or coastal cities of India.

\section{KEYWORDS}

Hypothyroidism, Prevalence, Thyroid Disorders, Dibrugarh, Assam.

HOW TO CITE THIS ARTICLE: Dutta PK, Dutta A, Kashyap H, et al. Prevalence of hypothyroidism in urban population of Dibrugarh town. J. Evolution Med. Dent. Sci. 2018;7(06):755-758, DOI: 10.14260/jemds/2018/171

\section{BACKGROUND}

According to a projection from various studies on thyroid disease, it has been estimated that about 42 million people in India suffer from thyroid diseases.[1] The prevalence of hypothyroidism in India is $11 \%$ compared with only $2 \%$ in the UK and $4.6 \%$ in the USA. Experts have argued that the reason behind the higher mean thyroid-stimulating hormone concentration and range in India compared with western countries is possibly linked to long-standing iodine deficiency in the country, which has only been partly corrected over the past 20 years. Compared with coastal cities (eg. Mumbai, Goa, and Chennai), cities located inland (eg. Kolkata, Delhi, Ahmedabad, Bangalore and Hyderabad) have a higher

'Financial or Other Competing Interest': None.

Submission 08-12-2017, Peer Review 25-01-2018,

Acceptance 31-01-2018, Published 05-02-2018.

Corresponding Author:

Dr. Anupam Dutta,

Assistant Professor

Department of Medicine,

Assam Medical College and Hospital,

Revti House, Purnananda Road, Shantipara,

Dibrugarh-786001, Assam, India.

E-mail: dranupamdutta80@gmail.com

DOI: $10.14260 /$ jemds $/ 2018 / 171$ (c) (i) $\ominus$ prevalence (11.7\% vs. 9.5\%).[2,3] Hilly areas like Kashmir has a higher prevalence of thyroid disorders (40.36\%) with high subclinical hypothyroidism (33\%).[4] North East India is surrounded by foot hills of Himalaya on North, East and South and may have higher prevalence of thyroid disorders owing to its geographical location. Hence, we have undertaken a community-based study to find the prevalence of thyroid disorders in Dibrugarh town of Upper Assam of North East India.

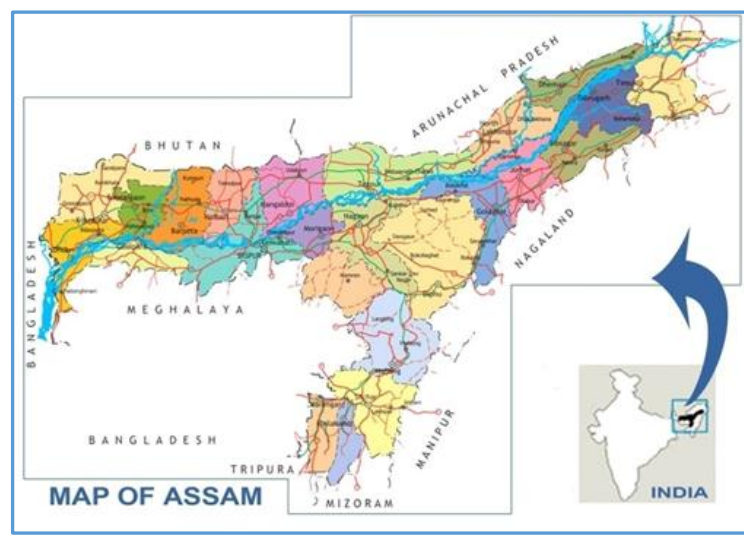

Image 1. Map of Assam showing Dibrugarh district (Indigo Coloured) second from the right on the Lower Bank of Brahmaputra 


\section{MATERIALS AND METHODS \\ Study Design}

This was a cross-sectional, community-based epidemiological study conducted in four community clinics, in four different wards of Dibrugarh town. Dibrugarh Municipality Board has a population of 1,39,565 (Census 2011) divided into 24 wards.[5] The wards were selected to represent equal number of Assamese, Bengali, Bihari and Marwari populations who are the major linguistic communities of Dibrugarh town. The primary outcome measure was to study the prevalence of hypothyroidism by measuring thyroid hormone levels in blood samples of willing individuals. Secondary outcome was to measure the prevalence of subclinical hypothyroidism, hyperthyroidism and subclinical hyperthyroidism. All male and female natives of Dibrugarh town, aged $>12$ years of age were asked to volunteer in thyroid camps held on every $2^{\text {nd }}$ and $4^{\text {th }}$ Friday and Saturday of every month from $1^{\text {st }}$ January 2015 to 31 ${ }^{\text {st }}$ December 2016. Participants were excluded if they were seriously ill, pregnant, had thyroid surgery or on any drugs containing heavy metals (Lithium, Amiodarone), steroids (oral or inhaled).

\section{Subjects}

Considering the urban population of Dibrugarh town 1,39,565 according to 2011 census and the Indian average prevalence of hypothyroidism to be $11 \%$, we calculated a sample size of 926 with $95 \%$ confidence interval and $2 \%$ error. Expecting a high prevalence, we screened a total of 1467 patients, out of which 117 patients were excluded due to inadequate data. 1350 patients were included in our study. Participants were selected through a single visit in 4 different community clinics on specified dates of week and screened by physicians.

\section{Sampling Method}

Four wards were selected randomly by lottery method out of 24 wards in Dibrugarh town. Pamphlets were distributed in the respective wards that thyroid camps will be held on specified days of the week, twice a month. In two wards, patients attended camps on every $2^{\text {nd }}$ and $4^{\text {th }}$ Friday of every month from $1^{\text {st }}$ January 2015 to $31^{\text {st }}$ December 2016. In rest of the two wards, patients attended camp on every $2^{\text {nd }}$ and $4^{\text {th }}$ Saturday of every month for the same duration. Out of the patients who attended the camp, those who fulfilled the inclusion criteria were selected and those who met the exclusion criteria were rejected. As random sampling method was not applied, this can be regarded as a limitation of this study.

\section{Study Procedure}

Participants underwent general examination by physicians in the clinics along with short clinical history before being included in the study. $5 \mathrm{~mL}$ of blood was collected in and sent to a central certified laboratory for Thyroid Assay. TSH level was performed by Ultrasensitive Sandwich Chemiluminescent Immunoassay. T3 and T4 was performed by Competitive Chemiluminescent Immunoassay. Based on their thyroid assay reports, they were divided into five groups namely Hyperthyroidism $(\mathrm{TSH}<0.1)$, Sub-clinical Hyperthyroidism (TSH 0.1 - 0.3), Euthyroid (TSH $0.3-5.5$ ) Sub-clinical Hypothyroidism (TSH 5.5 - 10) and Overt Hypothyroidism (TSH > 10). Clinical history of prior treatment for any thyroid disorder and presence of Anti-TPO positivity was taken into account.

\section{Statistical Analysis}

Statistical analysis was performed using SPSS for Windows (Version 13.0).

\section{RESULTS}

A total of 1467 patients were screened, of which 117 patients were excluded due to inadequate data. 1350 patients were included in our study. Their mean age was 42.7 (+ 1.3 SD) years. 32 (2.4\%) patients were below the age of 20 years, 224 (16.60\%) patients from 21 - 30 years, 411 (30.44\%) patients were 31 - 40 years, $343(25.40 \%)$ patients were 41 - 50 years, $213(15.80 \%)$ patients were $51-60$ years and $127(9.40 \%)$ patients were above 60 years respectively. 229 (16.97\%) patients were males and $1121(83.03 \%)$ were females.

Most of the subjects were in the $4^{\text {th }}$ decade $(30 \%)$ and $5^{\text {th }}$ decade (25\%) amounting to more than half of the total subjects $(55 \%)$. The youngest subject was 12 years and the eldest subject was 79 years old. The extremes of the ages had minimum representation. $2.3 \%$ subjects were in their $2^{\text {nd }}$ decade and $9.4 \%$ subjects in their $>7$ th decade.

\begin{tabular}{|c|c|c|c|c|c|c|c|c|c|c|c|}
\hline \multirow{3}{*}{$\begin{array}{l}\text { Age } \\
\text { Group }\end{array}$} & \multirow{3}{*}{ Total } & \multicolumn{10}{|c|}{ TSH Level } \\
\hline & & \multicolumn{2}{|c|}{$\begin{array}{c}<0.1 \\
\text { (Hyperthyroidism) }\end{array}$} & \multicolumn{2}{|c|}{$\begin{array}{c}0.1-0.3 \\
\text { (Sub-clinical } \\
\text { Hyperthyroidism) }\end{array}$} & \multicolumn{2}{|c|}{$\begin{array}{c}0.3-5.5 \\
\text { (Normal) }\end{array}$} & \multicolumn{2}{|c|}{$\begin{array}{c}5.5-10 \\
\text { (Sub-clinical } \\
\text { Hypothyroidism) }\end{array}$} & \multicolumn{2}{|c|}{$\begin{array}{c}>10 \text { (Overt } \\
\text { Hypothyroidism) }\end{array}$} \\
\hline & & Male & Female & Male & Female & Male & Female & Male & Female & Male & Female \\
\hline $12-20$ & 32 & 0 & 0 & 0 & 0 & 3 & 21 & 1 & 4 & 0 & 3 \\
\hline $21-30$ & 224 & 1 & 6 & 0 & 2 & 22 & 124 & 1 & 37 & 0 & 31 \\
\hline $31-40$ & 411 & 3 & 9 & 0 & 5 & 25 & 189 & 12 & 93 & 17 & 58 \\
\hline $41-50$ & 343 & 2 & 8 & 0 & 4 & 30 & 158 & 10 & 74 & 11 & 46 \\
\hline $51-60$ & 213 & 0 & 9 & 1 & 3 & 21 & 111 & 9 & 33 & 5 & 21 \\
\hline $60+$ & 127 & 1 & 3 & 1 & 1 & 37 & 39 & 7 & 17 & 9 & 12 \\
\hline \multirow{2}{*}{ Total } & \multirow{2}{*}{1350} & 8 & 35 & 2 & 15 & 138 & 642 & 40 & 258 & 42 & 171 \\
\hline & & \multicolumn{2}{|c|}{$42(3.11 \%)$} & \multicolumn{2}{|c|}{$17(1.26 \%)$} & \multicolumn{2}{|c|}{$780(57.78 \%)$} & \multicolumn{2}{|c|}{$298(22.07 \%)$} & \multicolumn{2}{|c|}{$213(15.78 \%)$} \\
\hline & & & & Table 1. & nograph & rofile & Patients & & & & \\
\hline
\end{tabular}

In our study, out of 1350 subjects 780 (57.78\%) patients had normal thyroid results. $213(15.78 \%)$ patients had overt hypothyroidism and $298(22.07 \%)$ patients had subclinical hypothyroidism. 41 (3.04\%) had hyperthyroidism and 17 $(1.26 \%)$ had subclinical hyperthyroidism. The percentage of male hypothyroid patients was $18 \%$ and female hypothyroid patients was $15 \%$. There were $17 \%$ male subclinical hypothyroid patients, whereas $23 \%$ female subclinical hypothyroid patients which was significantly higher. 


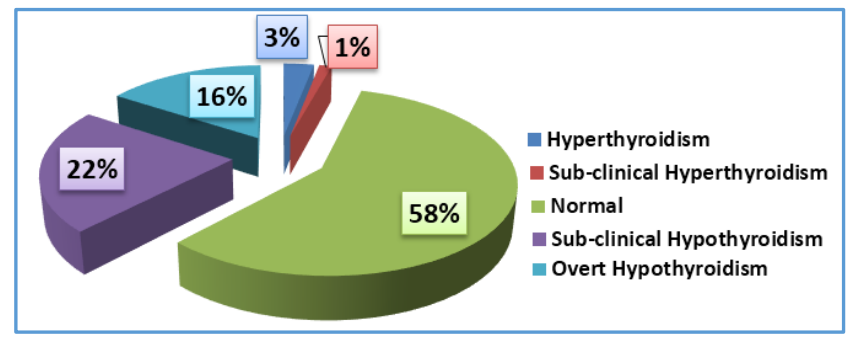

Figure 1. Percentage of Thyroid Disorders in Urban Population of Dibrugarh Town

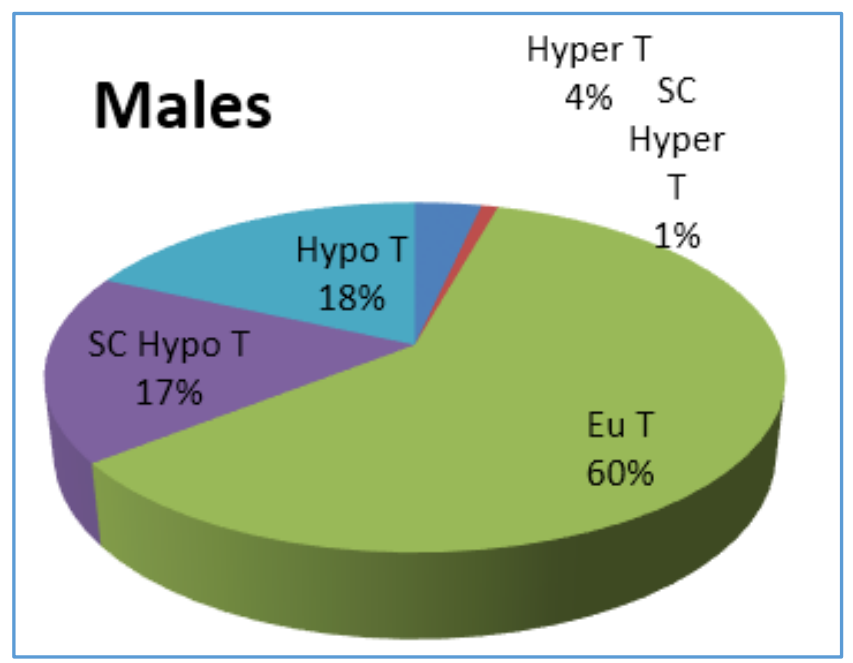

Figure 2. Percentage of Thyroid Disorders in Male Subjects

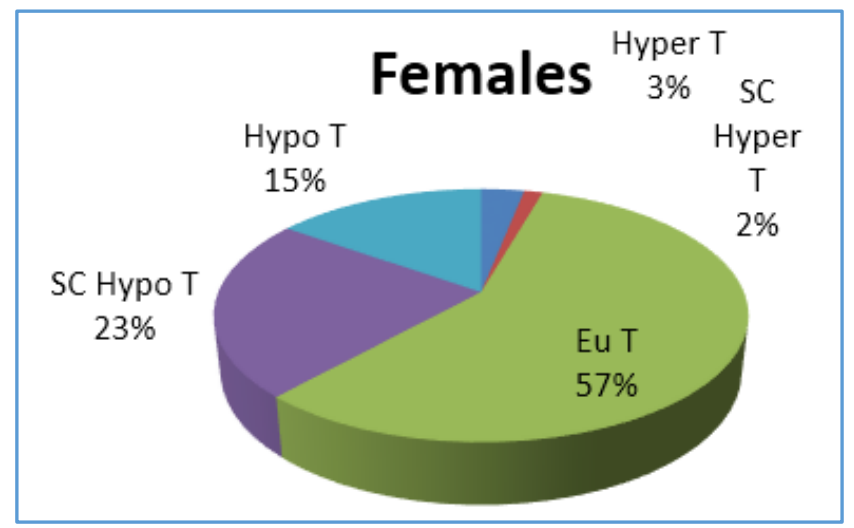

Figure 3. Percentage of Thyroid Disorders in Female Subjects

A cross-sectional, multi-centre, epidemiological study was conducted in eight major cities (Bangalore, Chennai, Delhi, Goa, Mumbai, Hyderabad, Ahmedabad and Kolkata) of India to study the prevalence of hypothyroidism among adult population. [3] The prevalence of hypothyroidism in the overall study population was $10.95 \%$. Among all cities Kolkata recorded the highest prevalence of hypothyroidism (21.67\%), while others showed comparable rates ranging from $8.88 \%$ (Hyderabad) to $11.07 \%$ (Delhi). Cities located in the inland regions of India (Delhi, Ahmedabad, Kolkata, Bangalore and Hyderabad) reported a significantly higher prevalence of hypothyroidism $(11.73 \%)$ than those (Mumbai, Chennai and Goa) in the coastal areas (9.45\%), $p=0.01$. We have compared their data with our results and is described below in Figure Number 4.

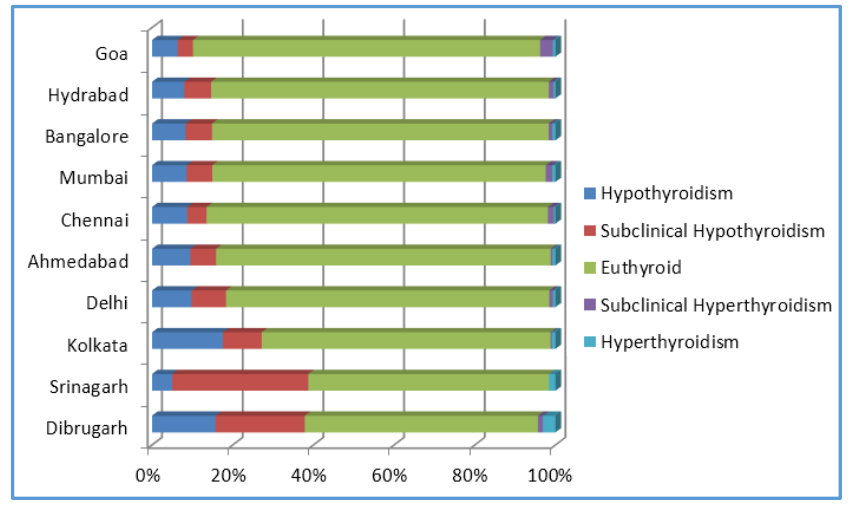

Figure 4. Comparison of Prevalence in Our Study with various Urban Cities of India[3]

\section{DISCUSSION}

In an epidemiological study from Cochin on 971 adult subjects, the prevalence of hypothyroidism was $3.9 \%$. The prevalence of subclinical hypothyroidism was also high in this study, the value being $9.4 \%$. In women, the prevalence was higher at $11.4 \%$ when compared with men, in whom the prevalence was $6.2 \%$. The same study showed that subclinical and overt hyperthyroidism were present in $1.6 \%$ and $1.3 \%$ of subjects participating in a community survey.[6]

In an Indian study covering a period of 10 years (1972 1981), out of all hypothyroid cases admitted to various referral hospitals $54 \%$ presented as overt hypothyroid, while $26 \%$ and $20 \%$ as mild (Bulleweiz clinical scoring system) and subclinical variety respectively. Our study showed that out of all hypothyroid cases, $57.3 \%$ patients had subclinical hypothyroidism and $41.7 \%$ had overt hypothyroidism.

In a hospital based study by Bania D and Das K in Barpeta district of Assam, 600 patients (56.33\% male and 41.67\% female) were studied and $9.67 \%$ had hypothyroidism, $4 \%$ had subclinical hypothyroidism, $4.17 \%$ had hyperthyroidism, $1.6 \%$ had subclinical hyperthyroidism and $6.67 \%$ were antiTPO positive.[7]

Hazarika J et al in a study on depressed patients from Tezpur, Assam found Subclinical hypothyroidism prevalence to be $6.5 \%$ and Overt hypothyroidism to be $3.2 \%$. Though the prevalence was seen in a selected cohort of depressed patients, their results were higher for subclinical hypothyroid when compared with similar studies.[8]

In a clinic-based study by Mahanta A et al from Guwahati, Assam, which studied 2456 samples, prevalence of overt hypothyroidism was $10.9 \%$ and that of subclinical hypothyroidism was $13.1 \%$. They concluded that high prevalence of overt hypothyroidism is probably due to referral bias to this clinic-based registry study; hence, this figure may be higher than the actual prevalence in the general population.[9] Though we cannot counter the referral bias in our study, but our observation was mostly in community clinics who came voluntarily or by spread of mouth awareness. The higher prevalence in our study cannot be entirely credited to referral bias.

Jailkhani R et al studied 612 (120 men and 492 women) for 18 months from an outpatient department in Srinagar, Jammu and Kashmir State of India, from where significant incidence of thyroid dysfunction, especially hypothyroidism has been reported. Overall prevalence of subclinical hypothyroidism was 33\% (206 of 612); prevalence of overt hypothyroidism was $5 \%$ (31 of 612); and prevalence of 
hyperthyroidism was $1.6 \%$ (10 of 612 ). Of the total 247 subjects with thyroid disorders, $17.8 \%$ were men (44) and 81.2\% were women (203).[3]

Dibrugarh town is surrounded by hilly areas and our results were closer to the prevalence of hypothyroidism in Jammu and Kashmir. In our study, 15.78\% patients had overt hypothyroidism and $22.07 \%$ patients had subclinical hypothyroidism. Our prevalence of overt hypothyroidism was close to the data from Kolkata which may be due to geographic reasons.[3] Chandra $\mathrm{AK}$ et al in a comparable geographical area of Gangetic basin in West Bengal found prevalence of hypothyroidism in 3814 subjects from all age groups to be even higher (29\%).[10] The high prevalence figures in Kolkata have ascertained that thyroid disorders in India are not confined to the conventional iodine-deficient Sub-Himalayan zone, but also extended to the plain fertile lands. This can also be extrapolated to the Brahmaputra basin in Assam.

\section{CONCLUSION}

The urban population of Dibrugarh town shows higher prevalence of clinical as well as subclinical hypothyroidism than Indian average and its results resemble the studies done in hilly areas like Jammu and Kashmir than other inland or coastal cities of India.

\section{REFERENCES}

[1] Unnikrishnan AG, Menon UV. Thyroid disorders in India: an epidemiological perspective. Indian Journal of Endocrinology and Metabolism 2011;15(Supp 2):S78-81.
[2] Bagcchi S. Hypothyroidism in India: more to be done. Lancet Diabetes Endocrinol 2014;2(10):778. www.thelancet.com/diabetes-endocrinology

[3] Unnikrishnan AG, Kalra S, Sahay RK, et al. Prevalence of hypothyroidism in adults: an epidemiological study in eight cities of India. Indian J Endocrinol Metab 2013;17(4):647-52.

[4] Jailkhani R, Ramachandrayya SA, Patil VS, et al. A hospital-based study of prevalence of thyroid dysfunction in Srinagar, Jammu and Kashmir state of India; International Journal of Medical Science and Public Health 2015;4(2):151-4.

[5] Dibrugarh city census 2011 data, Dibrugarh metropolitan region. www.census2011.co.in/census/city/189dibrugarh.html

[6] Menon UV, Sundaram KR, Unnikrishnan AG, et al. High prevalence of undetected thyroid disorders in an iodine sufficient adult south Indian population. J Indian Med Assoc 2009;107(2):72-7.

[7] Bania D, Das K. A study on prevalence of thyroid function disorders amongst the population of Barpeta District, Assam. IOSR Journal of Dental and Medical Sciences (IOSR-JDMS) 2017;16(2) Ver. VIII: 47-50.

[8] Hazarika J, Kalita KN, Sharma M, et al. Thyroid profile in depression: a cross-sectional study from North-East India. Int J Res Med Sci 2017;5(3):1066-70.

[9] Mahanta A, Choudhury S, Choudhury SD. Prevalence of hypothyroidism in Assam: a clinic-based observational study. Thyroid Res Pract 2017;14(2):63-70.

[10] Chandra AK, Tripathy S, Mukhopathyay S, et al. Studies on endemic goitre and associated iodine deficiency disorders (IDD) in a rural area of the Gangetic West Bengal. Indian J Nutr Diet 2003;40:53-8. 